\title{
Accounting
}

\section{Integrating ethical sensitivity through religiosity in accounting education}

\author{
Jaspal Singh $^{a^{*}}$, Muhammad Sadiq ${ }^{\mathrm{b}}$ and Kamaljeet Kaur ${ }^{\mathrm{c}}$
}

${ }^{a}$ Sunway University Business School, Malaysia

${ }^{b}$ School of Accounting \& Finance, Faculty of Business \& Law, Malaysia

'Infrastructure University Kuala Lumpur, Malaysia

\begin{tabular}{l}
\hline C H R O N I C L E \\
\hline Article history: \\
Received March 182020 \\
Received in revised format May \\
262020 \\
Accepted July 182020 \\
Available online \\
July 182020 \\
\hline Keywords: \\
Ethical sensitivity \\
Religiosity \\
Accounting education \\
Human governance
\end{tabular}

\section{A B S T R A C T}

\begin{abstract}
Accounting is part of everyone's life and affects all stakeholders who are the users of the accounting information. Organizations are created to serve their stakeholders and governments are supposed to govern, regulate and safe guard the interests of these stakeholders. Whilst accounting frequently experiences behavioral and human governance issues, this study explores the level of ethical sensitivity and its relationship with religiosity among final year accounting students in Malaysia. This study addresses the lack and the need to inculcate religiously orientated topics to be embedded and inculcated in the syllabi of bachelor of accounting, because being intrinsically religious makes an individual ethical. A quantitative research method is applied where questionnaires are administered to final year undergraduate accounting students at selected public and private universities in Malaysia. This study utilized Shaub's ethical sensitivity questionnaire to measure ethical sensitivity and Allport's Religiosity Orientation Scale to measure religiosity. Students are found to be ethically sensitive and by using Binary Logistic Regression, it is concluded that ethical sensitivity is influenced by intrinsic religiosity but not influenced by social extrinsic religiosity and personal extrinsic religiosity and may give some insights to the prospective employer on the selection criteria of future accountants and auditors, with regards to ethical conduct.
\end{abstract}

\section{Introduction}

Principle-based accounting standards with fair value accounting allows preparers to exercise judgement on reporting, hence, financial reports might not always be representative of firms' value. If accountants are not ethical and not conscious about ethical sensitivity, the flexibility without professional skepticism may result in earnings management (Jacob \& Jorgensen, 2007; Marra et al., 2011; Perols \& Lougee, 2011). Recent accounting scandals of Toshiba, Theranos, and Barclays Bank indicated that earnings management needs further scrutiny. Therefore, alternative measures must be taken into consideration to curtail earnings management. Thus, it is argued that ethical reasoning should be addressed rather than solely focusing on greater transparency and introducing new rules, where the individual will be able to justify their actions and nurtured well to serve the society by projecting good human governance. It is vital to look into the cognitive ethical development of individuals to understand behavioral accounting. The psychology of ethical reasoning is the common foundation of ethical development, ethical judgement and ethics education, which is based on Kohlberg's theory of ethical reasoning. Based on Kohlberg's six-stages cognitive ethical

* Corresponding author.

E-mail address: jaspalj@sunway.edu.my (J. Singh) 
reasoning model, Rest (1983) developed a four-component model, namely ethical sensitivity, ethical judgement, ethical motivation and ethical character. In Malaysia, approximately $32 \%$ of the accounting students were prepared to cheat in examination and if given opportunity at the work place, then $14 \%$ of these students are willing to accept bribe (O'Leary \& Mohamed, 2006, 2008). Some researchers (Albrecht \& Sack, 2000) argue that the academics have to equally share the blame of corporate failures, because they did not address the important issue of integrity, ethics and values. Thus, it is suggested by Saat et al. (2010) to improve the ethical sensitivity by reshaping the ethical behavior of Malaysian accountants. Firms may find it difficult to curtail fraud because achieving financial targets supersede good ethical culture. In 2013, KPMG Malaysia's fraud survey opined that firms can only prevent fraudulent activities when managers and employees believe that ethics is core in a management's business methods. In 2016, Ernst \& Young exemplify in the 14th Global Fraud survey that approximately 50\% of their respondents justify unethical behavior to meet financial targets while one-third of the respondent justify inappropriate conduct.

This study examines the central problem that is accounting fraud, which is caused by the inability to identify unethical business scenarios or lack of ethical sensitiveness. Ethical sensitivity is affected by the level of religiosity and this study identifies the link between religious teaching and the improvement of the level of ethical sensitivity, hence promote religious education to be inculcated in the teaching of accounting ethics for students at tertiary level. Being intrinsically religious will have a positive impact on the ability of an individual to be ethically more sensitive and be free of wrong doings.

\section{Literature review}

\subsection{Ethical sensitivity}

The common foundation of the psychology provides four psychological processes that an individual needs to possess to behave morally. Lawrence Kohlberg's theory gives focus on a six-stage model of cognitive process, which provides foundation of moral reasoning. For individuals to behave morally, first they need to fulfil ethical sensitivity, which enable individuals to recognize and interpret a situation that may impact others. Second, ethical character, which is the will power to perform an ethical conduct. Third, ethical judgement, which enable individuals to judge what is right or wrong. Last, ethical motivation, which enable individuals to give priority to moral values over the inherent values. In a given scenario, ethically sensitive individual must perceive an issue that has an ethical implication (Martinov-Bennie \& Mladenovic, 2015). Individual with lack of sensitivity to the needs and welfare of others may fail to recognize and perceive an ethical issue (Frank, Ofobike, \& Gradisher, 2009). Using American and Taiwanese students' data, prior research, Ho (2007) examined the ethical sensitivity among students, where ethical sensitivity was found to have a significant association with ethical intention. Ethical sensitivity is greater when there is a dedicated subject on ethics being taught to students (Triki, 2011), and it serves as a triggering mechanism that begins the ethical decision-making process (Karakoc, 2016). Ethical sensitivity is unique as it is a situational based questioning, (Shawver and Miller, 2017) and cannot be interpreted similar to ethical judgement, (Musbah \& Cowton, 2016; Muslichah et al., 2017).

It is also vital to establish here that even though Rest (1986); cited by Chan and Leung (2006) established that all the four components are related, it is ethical sensitivity that is the first component that corresponds with an individual, before it reaches to the other three components. Therefore, ethical sensitivity is the window to the other three components of the Rest's fourcomponent model and being the first point of contact, it is vital to establish a better understanding about ethical sensitivity and its relationship with its predictors. Rest (1983) stated that the failure of any one component will lead to the unethical behavior conducted by an individual. Chan and Leung (2006) echoed the statement made by Rest (1983) that all the four components of the four-component model interact with each other. Ethical sensitivity is a situational based questioning, and cannot be interpreted similar to ethical judgement, therefore making ethical sensitivity not as popular to be studied upon as ethical judgement (Myyry, 2003; Chan and Leung, 2006). Due to limited instruments available to capture and analyze it, very few literatures have discussed ethical sensitivity (Chan \& Leung, 2006; Singh, 2013), therefore, to fill the gap in the literature and research, this study will focus on the first component, which is the ethical sensitivity.

\subsection{Religiosity}

Devotion to God by following the principles that is created by God is known as religiosity (McDaniel \& Burnett, 1990). Religion is not seen to be necessary to maintain good morality in capitalist world, thus, the gap between religion and governments is widening in terms of the need of such reconciliation. Some researchers opined that there is a significant relationship between religious commitment and ethical reasoning (Singh, 2013). Singh (2013) in his study exemplified that the religious individuals are less likely to get involved in any unethical practices. Similarly, some researchers (Bloodgood et al., 2007) suggest that students who are more frequently engaged in worship services are less likely to cheat as compared to those who are less engaged in worship services. Individuals are more motivated to have better ethical awareness when they strongly practice their religion 
(Saat et al., 2009), suggesting a significant association between one's religiosity and ethical sensitivity. Further, it was found that students who attend religious schools were found to have higher levels of ethical sensitivity. Prior studies differentiated religious motivation into two different types i.e. intrinsic and extrinsic religiousness. The intrinsically motivated person lives his or her religion whereas, the extrinsically motivated person uses his or her religion (Allport, 1950; Vitell et al., 2005). Individuals with extrinsic religious motivations do not practice the values of any particular religion but appear to be religious. However, intrinsic religiosity individuals internalize religion's teaching, and therefore they are supposed to be ethically sensitive (Singh, 2013). Prior studies (Gorsuch and McPherson, 1989) further categories extrinsic religiosity into two subcategories i.e. personal extrinsic and social extrinsic. Extrinsic personal religiosity inclined individuals to be ethical not sensitive and exploit religion for personal benefits. Whereas the extrinsic social religiosity inclined individuals to exploit religion for social needs. Therefore, it is argued that intrinsic religiousness is a significant determinant of consumer ethical beliefs, however, extrinsic religiousness is not related to those beliefs.

\section{Hypotheses Development}

It is argued that the study of ethical development of accounting practitioners should start with the accounting students, because the accounting students are the future accounting practitioners. Thus, this study was motivated to empirically examine the effects of the level of religiosity on the ethical sensitivity and examine the ethical sensitivity process of accounting students. Prior studies (Saat et al., 2010; Vitell et al., 2005) exemplified that there is a significant association between religiosity and ethical sensitivity. Although Vitell et al. (2005) conducted the study using consumers' data. However, congruent with the study of Maisarah et al. (2010), this study collected data from accounting students, and thus hypothesize that:

$\mathrm{H}_{1}$ : There is a significant relationship between the intrinsic religiosity and ethical sensitivity of accounting students.

Some researchers (Vitell et al., 2005; Saat et al., 2010) have differentiated between extrinsic and intrinsic religiosity. Vitell et al. (2005) explained the distinction between extrinsic personal and social religiosity and its impact on ethical sensitivity. Extrinsic personal religiosity and extrinsic social religiosity are two subcategories of extrinsic religiosity, therefore, the second and third hypotheses examined if there is any relationship between the extrinsic social and personal religiosity and ethical sensitivity of accounting students. Thus, we hypothesize that:

$\mathrm{H}_{2}$ : There is a significant relationship between the extrinsic social religiosity and ethical sensitivity of accounting students. $\mathrm{H}_{3}$ : There is a significant association between the extrinsic personal religiosity and ethical sensitivity of accounting students.

Ethical sensitivity enables an individual to recognize and interpret any ethical issue that might overcome in a given situation. Ethical sensitivity also enables individuals to be able to predict the outcome of their actions. Congruent with the study of Saat et al. $(2009,2010)$, this study investigates the ethical sensitivity of accounting students in Malaysia. However, this study examined the level of ethical sensitivity of accounting students in Malaysia using an instrument designed by Shaub (1989), and thus we hypothesize that:

$\mathrm{H}_{4}$ : Accounting students in Malaysia are ethically sensitive.

\section{Research Methodology}

\subsection{Subjects}

The respondents of this study were final year accounting students enrolled in a four-year bachelor of accountancy program, using syllabi recommended by the Malaysian Institute of Accountants (MIA) adopted by institutions of higher learning in Malaysia. The admission criteria, program structure, academic curriculum and the teaching and learning are quite similar among the universities selected for the study. As response rate is low for studies based on primary data (Sekaran \& Bougie, 2010), 700 questionnaires were prepared to be distributed to eight institutions of higher learning to attain a sample size of about 300 . From the eight institution of higher learning that was selected, only four responded and agreed to participate, hence 350 questionnaires were distributed to these four institutions of higher learning, with only 262 questionnaires collected, of which 49 were unusable, leaving only 213 that were usable.

\subsection{Instruments}

The professional auditing scenario of the auditor's opinion questionnaire (AOQ), was developed specifically to measure ethical sensitivity by Shaub (1989). The scenario contains four paragraphs, which was created to make it easy to read and does not put off the respondents as to appear to be too lengthy. At the bottom of the scenario there are three lines created for each of the four paragraphs for the respondents to write down the ethical issues which they think are embedded in the scenario (Shaub, 1989). 
In this study, the scenario used to measure ethical sensitivity adopted similar scenario with minor amendments to fit into the Malaysian context and the reliability and validity of the questionnaire is proven by prior studies (Shaub, 1989; Shaub et al., 1993; Chan \& Leung, 2006). Respondents were required to jot down three ethical issues that are embedded in the scenario. Regardless of the importance of ethical sensitivity, each recognition of the ethical issue scores one mark (Chan \& Leung, 2006; Reza et al., 2019). Shaub's three ethical sensitivity instrument are, staff failing to charge time required completing the job, referred as eating hours. Second, office time to write a note to a prospective employer, referred as using firm time for personal matter. Third, subordination of an auditor's judgment over an issue involving generally accepted accounting principles referred as subordination of judgment (Shaub, 1989). A respondent will be categorized as ethically sensitive, if is able to identify at least two out of the three embedded ethical issues If a respondent is not able to identify any ethical issue or if only able to identify one out of the three embedded ethical issues, then the respondent is categorized as not ethically sensitive.

Donahue (1985); cited by Burks (2006); O'Fallon and Butterfield (2005); Vitell et al. (2005) claims that Allport and Ross's religiosity orientation scale is the most widely used instrument to measure the religiousness of individuals. Numerous studies on religiosity have been utilized religiosity orientation scale instrument. Gorsuch and McPherson (1989) reported reliability of 0.83 for intrinsic religiosity. The reliability reported for personal extrinsic of religiosity is 0.57 and 0.58 for social extrinsic of religiosity. Therefore, Gorsuch and McPherson's (1989) religiosity orientation scale was used to measure religiosity that is a revised version of Allport and Ross's scale. The purpose of religiosity orientation scale is to measure the religiousness of an individual and is not to determine whether or not an individual is religious Burks (2006). Gorsuch and McPherson (1989) posited that religiosity orientation scale is categorized into two major constructs, one is known as extrinsic religiosity (E) and the other is known as intrinsic religiosity (I). The extrinsic religiosity can be further categorized as extrinsic personal religiosity (Ep) are individuals who are personally oriented and extrinsic social religiosity (Es) are individuals who are socially oriented. Amendments made to make the questionnaire more general and universal, to fit the multi-racial and multi religion societies in Malaysia. For example, the phrase 'going to church' was replaced with 'place of worship', was replaced in three out of fourteen questions in the religiosity orientation scale used in this study.

Religiosity orientation scale contains fourteen questions and uses a five-point Likert scale as a base of measurement, with $1=$ disagree strongly up to $5=$ agree strongly. From the given fourteen questions, eight questions are to test the intrinsic religiosity construct and the rest of the six questions are to test the extrinsic religiosity construct. The complete questionnaire for religiosity orientation scale is shown as appendix B. Item one, three, four, five, seven, ten, twelve and fourteen form the intrinsic religiosity construct. To improve reliability of the questionnaire, out of the eight items for the intrinsic religiosity, item three, ten and fourteen are reversely worded to test religiousness of the respondents. The remaining six questions are to test extrinsic religiosity construct and are divided into personal extrinsic and social extrinsic construct. Three items are to test the extrinsic social construct, namely item two, eleven and thirteen and items six, eight and nine are to test the intrinsic social construct.

\section{Data analysis and results}

From the 350 questionnaires that were sent out only $262(74.9 \%)$ respondents returned the questionnaires from which only 213 $(81.3 \%)$ were usable. The descriptive analysis of the respondents is as projected in Table 1 where $41.8 \%$ of respondents were males and 58.2\% were females. The other important descriptive statistics that need to be highlighted and explored further is ethical sensitivity. Using Shaub's (1989) ethical sensitivity instrument, three scenarios were being expected of the respondents, namely failing to charge time, using time for personal matter and subordination of judgement. As per Table 1, from the three scenarios listed, it can be concluded that scenario 'failing to charge time' was being able to be identified by $57.3 \%$ of the respondents. For scenario 'using time for personal matter' was being able to be identified by only a mere $15 \%$ of the respondents. The last of the three scenarios 'subordination of judgement' was being able to be identified by $78.4 \%$ of the respondents.

\section{Table 1}

Demographic information and ethical sensitivity level and identification

\begin{tabular}{lll}
\hline Ethical Sensitivity Scenario Issues & Not Identified & Identified \\
\hline 1. Failing to charge time & $91(42.7 \%)$ & $122(57.3 \%)$ \\
2. Using time for personal matter & $181(85 \%)$ & $32(15 \%)$ \\
3. Subordination of judgement & $46(21.6 \%)$ & $167(78.4 \%)$ \\
\hline Gender & $89(41.8 \%)$ & \\
Male & $124(58.2 \%)$ & \\
Female & & \\
\hline Level of Ethical Sensitivity & $96(45.1 \%)$ & \\
Not ethically sensitive & $117(54.9)$ & \\
Ethically sensitive &
\end{tabular}


Respondents that were able to identify at least two of the three embedded ethical issue in the given scenario were categorized as ethically sensitive and if are able to recognize only one of the three embedded ethical issue or not able to recognize any issue in the given scenario, the respondent will be categorized as ethically not sensitive (Chan \& Leung, 2006). Referring to Table 1, it can be concluded that $54.9 \%$ of the respondents are ethically sensitive and $45.1 \%$ of the respondents are ethically not sensitive.

\subsection{Logistic Regression}

This study uses a binary logistic regression to examine the relationship between the independent variables i.e. extrinsic social religiosity, extrinsic personal religiosity and intrinsic religiosity and the dependent variable i.e. ethical sensitivity. Binary logistic regression is used when the dependent variable is categorical or dichotomous and is less affected when the variable does not fulfil the normality criteria and accommodates nonmetric variable through dummy variable coding. Other favorable quality of logistic regression is that it does not require the assumptions of linearity between the independent and dependent variables. Further logistic regression excludes from the assumptions of normality and homoscedasticity, which makes the binary logistic regression more robust (Hair et al., 2010). Binary logistic regression uses the odds function model to describe its equation and given the predictors that will be tested for its relationship with ethical sensitivity, the following equation is derived; $\ln$ (ODDS) $=\beta_{0}+\beta_{1}(\mathrm{Ep})+\beta_{2}(\mathrm{Es})+\beta_{3}$ (Intrinsic), where 'Ep' represents extrinsic personal religiosity orientation, 'Es' represents extrinsic social religiosity orientation and 'Intrinsic' represents intrinsic religiosity orientation. To improve the $\mathrm{R}^{2}$ of this study, thirty outliers were identified and removed from the data set. The binary logistic regression was utilized again to examine the relationship between the dependent variable and independent variables. The binary logistic regression equation can be derived from the Table 2 and the equation for the binary logistic equation is as follows,

$$
\begin{aligned}
& \ln (O D D S)=-0.529-0.024(E p)-0.111(E s)+0.635(I n t) \\
& E p=\text { extrinsic personal religiosity orientation } \\
& E s=\text { extrinsic social religiosity orientation } \\
& \text { Int }=\text { intrinsic religiosity orientation }
\end{aligned}
$$

Further explanation is captured on the Hosmer and Lemeshow test Table 2 shows a significance value of 0.201 , which is not significant and indicates that the non-significant chi square shows that the data fit the model well. Christensen (1997) and Hosmer and Lemeshow (2000) explained that in logistic regression models, the goodness of fit of the model is established by the non-significance of the Hosmer and Lemeshow's test. The next important observation is shown in Table 2 of the classification table shows a predicted overall percentage of 52.5, which indicates that, the overall success rate in classification of data into being ethically sensitive and ethically not sensitive, without using the model is $52.5 \%$, which is the threshold value. The inference made is that this model is able to predict $66.1 \%$ of the probability of the respondents' level of ethical sensitivity from the predictability without this model at $52.5 \%$ and the Cox \& Snell R Square and Adjusted R-Square are recorded at 0.131 and 0.174 as shown in Table 2 and Table 3.

Table 2

Logistic regression report

\begin{tabular}{lccc} 
& B & Wald Value & Sig. \\
\hline Extrinsic Personal & $\mathbf{- 0 . 0 2 4}$ & 0.009 & 0.926 \\
Extrinsic Social & $\mathbf{- 0 . 1 1 1}$ & 0.255 & 0.614 \\
Intrinsic & $\mathbf{- 0 . 7 8 5}$ & 10.78 & $\mathbf{. 0 0 1 *}$ \\
Constant & $\mathbf{- 0 . 5 2 9}$ & 0.064 & 0.8 \\
\hline
\end{tabular}

\begin{tabular}{|c|c|c|c|c|}
\hline & & \multicolumn{3}{|c|}{ Predicted } \\
\hline & & $\begin{array}{l}\text { Ethically Not } \\
\text { Sensitive }\end{array}$ & Ethically Sensitive & $\%$ Correct \\
\hline \multirow{3}{*}{$\begin{array}{c}\text { Classification Table for } \\
\text { Predictability } \\
\text { Step } 0\end{array}$} & Ethically Not Sensitive & 0 & 87 & 0 \\
\hline & Ethically Sensitive & 0 & 96 & 100 \\
\hline & Overall \% & & & 52.5 \\
\hline \multirow{3}{*}{$\begin{array}{l}\text { Classification Table for } \\
\text { Predictability with Model } \\
\text { Step } 1\end{array}$} & Ethically Not Sensitive & 51 & 36 & 58.6 \\
\hline & Ethically Sensitive & 26 & 70 & 72.9 \\
\hline & Overall \% & & & 66.1 \\
\hline \multirow[t]{2}{*}{ Step 1} & Cox \& Snell R ${ }^{2}$ & Adjusted $\mathrm{R}^{2}$ & \multicolumn{2}{|c|}{ Hosmer \& Lemeshow Test } \\
\hline & 0.131 & 0.174 & Chi-square $=11.006$ & Sig. $=0.201$ \\
\hline
\end{tabular}

*significant at $1 \%$

Table 3

The results of regression analysis 
Consistent with the findings of Vitell et al. (2005); Saat et al. (2009) and hypothesis 1, our findings show a significant relationship between the intrinsic religiosity and ethical sensitivity, suggesting that the individuals that internalize the religious teachings are more ethically sensitive and intrinsically religious. Moreover, some researchers argue that the extrinsic social religiosity inclined individuals to be ethically not sensitive, because these individuals use religion for social needs. In fact, these individuals do not practice the values of any particular religion. In line with the findings of Vitell et al. (2005), Okeke and Nwankpa (2018) and Saat et al. (2009), our findings reject the hypothesis 2 that examined the relationship between extrinsic social religiosity of accounting students and ethical sensitivity. The third hypothesis empirically investigate the extrinsic personal religiosity of accounting students and ethical sensitivity. In consistent with the hypothesis 3 , our findings suggest that extrinsic personal religiosity inclined individuals to take religion for personal relief reasons, and thus these individuals are ethically not sensitive. The final hypothesis examined whether accounting students in Malaysia are ethically sensitive. It is concluded that $54.9 \%$ of the respondents are ethically sensitive, as these respondents were able to identify at least two issues out of the three that are being embedded in the auditing scenario.

\section{Conclusion and future research.}

This study has explored one of the least discussed components of ethics, known as ethical sensitivity, using a scenario-based questionnaire, created based on accounting and auditing related domains. Limited studies have examined ethical sensitivity relationship with religiosity, and this study is not attempting to know whether an individual is religious, rather to know the level religiousness and to regress it against ethical sensitivity. By logistic regressive modelling, this study has found out that there is no significant association between ethical sensitivity and extrinsic social religiosity of accounting students. The second hypothesis concludes that there is no relationship between the ethical sensitivity and extrinsic personal religiosity of accounting students. The third hypothesis finds that there is a significant relationship between ethical sensitivity and intrinsic religiosity of accounting students. Slightly more than half of the respondents are ethically sensitive. Further on the discussion, those individuals that are inclined towards being socially extrinsic on religiousness are not ethically sensitive. The next investigation also shows that those individuals that are inclined towards being personally extrinsic on religiousness are not ethically sensitive. But those individuals that are inclined towards being intrinsic on religiousness are ethically sensitive. With numerous accounting fraud that had adverse effects on society, it is important that we acknowledge these damages that accounting fraud can force upon the society. To ascertain the faith of the users of accounting information on the credibility and integrity of financial reports. Converging with IFRSs, principles-based accounting and fair value accounting will have an impact on the way how accounting numbers will be looked at and interpreted. Because the shift from historical cost accounting to fair value accounting, the concept of 'faithful representation' will be more dominant than of 'reliability', therefore, ethical measurement, ethical recognition and ethical disclosure of financial statement is going to be ever more important. This study explored that financial reports are not representing the actual health and wealth of the reported entity. In other words, the financial reports are not true and fair, as the preparers of the reports might not be complying with relevant rules and regulations. Such malpractices which are a result of unethical behavior to show inflated profits will ultimately result in reducing the wealth of the shareholders. Accounting fraud may take place when the agent of the firm acts in its self-interest, rather than in the interest of the principal and when exposed it will shake the confidence of the public and other users of financial reports, ultimately it might bring down the social standings of society as well as it might cause economic and political instability. Therefore, to curtail accounting fraud by educating the future accounting practitioners, accounting ethics education may possibly be the solution. As part of the curriculum to tackle ethical issues, accounting students should be more exposed to ethical dilemma to solve the ethical problems. This study categorized its dependent variable, ethical sensitivity into two categories, ethically sensitive and ethically not sensitive. Therefore, statistical inferences such as logistic regression had to be used and it limited the scope of analysis of this study. Moderating and mediating variable can be introduced into the research framework and future research can look at introducing interaction hypotheses to the study.

\section{References}

Albrecht, W.S. \& R.J. Sack. (2000). Accounting education: charting the course through a perilous future. American Accounting Association. Accounting Education Series, 16, 1-72.

Allport, G. W. (1950). The Individual and His Religion: A Psychological Interpretation. New York: MacMillan.

Salleh, A., \& Ahmad, A. (2008). Human Governance: a paradigm shift in governing corporations. MPH Group Pub.

Bloodgood, J.M., Turnley, W.H. \& Mudrack, P. J. (2008). The influence of ethics instruction, religiosity, and intelligence on cheating Behavior. Journal of Business Ethics, 82, 557-571.

Burks, B.D. (2006). The Impact of Ethics Education and Religiosity on the Cognitive Moral Development of Senior Accounting and Business Students in Higher Education. (Doctor of Philosophy Thesis). Nova Southeastern University.

Chan, Y.S.S. \& Leung, P. (2006). The effects of accounting students' ethical reasoning and personal factors on their sensitivity. Managerial Auditing Journal, 21(4), 436-457.

Christensen, S. (1997). Log-Linear Models \& Logistic Regression. New York: Springer-Verlag. 
Hosmer, W. D., \& Lemeshow, S. (2000). Applied Logistic Regression. $2^{\text {nd }}$ ed. Wiley.

Frank, G., Ofobike, E., \& Gradisher, S. (2009). Teaching business ethics: A quandary for accounting educators. Journal of Education for Business, 85(3), 132-138.

Gorsuch, R. \& McPherson, S. (1989). Intrinsic/extrinsic measurement: I/E revised and single-item scales. Journal of Scientific Study of Religion, 28(3), 348-354.

Hair, J.F., Black, W.C., Babin, B.J. \& Anderson, R.E. (2010). Multivariate Data Analysis: A Global Perspective. $7^{\text {th }}$ ed. Person Education.

Ho, Y. H. (2007). Undergraduate Accounting Students' Perceptions of Accounting Ethics: A Cross-Cultural Comparative Study. (Doctor of Philosophy Thesis). University of Minnesota.

Jacob, J. \& Jorgensen, B.N. (2007). Earnings management and accounting income aggregation. Journal of Accounting and Economics, 43, 369-390.

Karakoc, E.Y. (2016). The relationship among ethical ideologies, ethical sensitivity and attitude of business students towards accounting. International Journal of Academic Research in Business and Social Sciences, 6(4), 72-85.

Marra, A., Mazzola, P., Precipe, A. (2011). Board monitoring and earnings management pre and post IFRS. The International Journal of Accounting, 46(2), 205-230.

Martinov-Bennie, N., \& Mladenovic, R. (2015). Investigation of the impact of an ethical framework and an integrated ethics education on accounting students' ethical sensitivity and judgment. Journal of Business Ethics, 127(1), 189-203.

McDaniel, S.W. \& Burnett, J.J. (1990). Consumer religiosity and retail store evaluative criteria. Journal of the Academy of Marketing Science, 18(2), 101-112.

Musbah, A., \& Cowton, C.J. (2016). The role of individual variables, organizational variables and moral intensity dimensions in Libyan management accountants' ethical decision making. Journal of Business Ethics, 134(3), 335-358.

Muslichah, M., Wiyarni, W. \& Maria. E. (2017). The effect of ethical sensitivity on ethical decision making with religiosity as moderating variable. International Review of Management and Marketing, 7(5), pp. 86-92.

Myyry, L. (2003). Components of Morality: A Professional Ethics Perspective on Moral Motivation, Moral Sensitivity, Moral Reasoning and Related Contructs Among University Students. (Doctor of Philosophy Thesis). University of Helsinki.

O'Fallon, M.J. \& Butterfield, K.D. (2005). A review of the empirical ethical decision-making literature: 1996-2003. Journal of Business Ethics, 59, 375-413.

Okeke, R., \& Nwankpa, L. (2018). Financial accountability, ethical issues and organizational citizenship behavior in fragile economic systems: The case of the Nigerian economy. Accounting, 4(4), 161-170.

O'Leary, C., \& Mohamad, S. (2008). The successful influence of teaching ethics on Malaysian accounting students. Malaysian Accounting Review, 7(2), 1-16.

O'Leary, C. \& Mohamed, S. (2006). A tri-national comparison of final year accountancy students ethical attitudes. Malaysian Accounting Review. 5(1), 139-157.

Perols, J.L. \& Lougee, B.A. (2011). The relation between earnings management and financial statement fraud. Advances in Accounting, 27(1), pp. 39-53.

Rest, J.R. (1983). “Morality”. In Flavell, J. \& Markman, E. (eds). Handbook of Child Psychology. $4^{\text {th }}$ ed. Vol. III, New York: Wiley.

Rest, J.R. (1986). Moral Development - Advances in Research and Theory. New York: Praeger.

Raza, A., Hussin, W., \& Majid, J. (2019). An explanatory review of audit market concentration and auditor workload in Malaysia. Accounting, 5(4), 135-144.

Saat, M. M., Porter, S., \& Woodbine, G. (2009). Does religiosity influence ethical sensitivity? An investigation on Malaysian future accountants. Management \& Accounting Review (MAR), 8(2), 17-41.

Saat, M. M., Porter, S., \& Woodbine, G. (2010). An exploratory study of the impact of Malaysian ethics education on ethical sensitivity. Journal of Business Ethics Education, 7, 39-62.

Sekaran, U. \& Bougie, R. (2010). Research Methods for Business: A Skill Building Approach. $5^{\text {th }}$ ed. John Wiley \& Sons.

Shaub, M.K. (1989). An Empirical Examination of the Determinants of Auditors' Ethical Sensitivity. (Doctor of Philosophy Thesis). Texas Tech University.

Shawver, T.J., \& Miller, W.F. (2017). Moral intensity revisited: Measuring the benefit of accounting ethics interventions. Journal of Business Ethics, 141(3), 587-603.

Singh, J., (2013). Determinants of Ethical Sensitivity Among Malaysian Accounting Students. (Doctor of Philosophy Thesis). Universiti Sains Islam Malaysia.

Singh, J. \& Poduval, M. (2009). Teaching of accounting ethics- An exploratory study on accounting lecturers in institutions of higher learning in Malaysia. (Paper). International Conference of Teaching and Learning. Kuching, Malaysia. 16-18, November.

Singhapakdi, A., Marta, J.K., Rallapalli, K.C. \& Rao, C.P. (2000). Toward an understanding of religiousness and marketing ethics: An empirical study. Journal of Business Ethics, 27(4), 305-319.

Triki, A. (2011). Accountants' Ethical Sensitivity. (Master of Science Thesis). Brock University.

Vitell, S. J., Paolillo, J. G., \& Singh, J. J. (2005). Religiosity and consumer ethics. Journal of Business Ethics, 57(2), 175-181. 


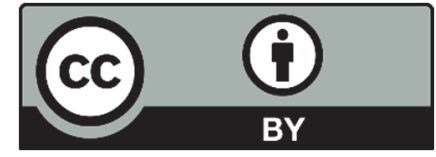

(C) 2020 by the authors; licensee Growing Science, Canada. This is an open access article distributed under the terms and conditions of the Creative Commons Attribution (CC-BY) license (http://creativecommons.org/licenses/by/4.0/). 